\title{
ANDERNACHT, Dietrich, ANDERNACHT, Helga, Regesten zur Geschichte der Juden in der Reichsstadt Frankfurt am Main
}

\section{Vincent Demont}

\section{(2) OpenEdition}

\section{Journals}

Édition électronique

URL : http://journals.openedition.org/ifha/1736

DOI : $10.4000 /$ ifha. 1736

ISSN : 2198-8943

Éditeur

IFRA - Institut franco-allemand (sciences historiques et sociales)

Référence électronique

Vincent Demont, «ANDERNACHT, Dietrich, ANDERNACHT, Helga, Regesten zur Geschichte der Juden in der Reichsstadt Frankfurt am Main », Revue de I'IFHA [En ligne], Date de recension, mis en ligne le 01 janvier 2009, consulté le 22 septembre 2020. URL : http://journals.openedition.org/ifha/1736 ; DOI : https://doi.org/10.4000/ifha.1736

Ce document a été généré automatiquement le 22 septembre 2020.

(C)IFHA 


\title{
ANDERNACHT, Dietrich, ANDERNACHT, Helga, Regesten zur Geschichte der Juden in der Reichsstadt Frankfurt am Main
}

\author{
Vincent Demont
}

1 Ce sont un monde, et une vie académique, qui sont ici offerts à la communauté scientifique : D.A., sa veuve et l'équipe réunie autour d'eux ont rassemblé près d'un demi-siècle de travail dans ces volumes, avec la restitution et l'indexation de plus de 9 000 documents. Ces regestes feront donc date : en prolongeant après 1400 l'œuvre d'édition entamée par I. Kracauer avant la Première Guerre mondiale et avec des sources aujourd'hui perdues, ils présentent deux siècles d'histoire d'une communauté ashkénaze dont l'importance et le rayonnement s'imposent alors non seulement à une ville, mais à l'Empire et presque à l'Europe entière.

2 Les deux volumes les plus récents, publiés à titre posthume, prennent ici un relief particulier : de 1520 à 1616, la "ruelle aux Juifs " de Francfort passe de 30 à 200 maisons, de quelques centaines à 2500 habitants. Cette poussée démographique correspond à un essor économique lié à celui des foires de la ville, mais aussi à l'endettement structurel de la ville, pour qui les Juifs sont une ressource. Les tensions intra-urbaines grandissent donc à mesure que la place de Francfort dans l'univers ashkénaze grandit, jusqu'à culminer, en 1614, dans un pogrom dont l'élection impériale constitue le déclencheur.

3 Si le lecteur est immergé dans le quotidien d'une venelle, il n'a donc guère d'effort à faire pour regarder bien au-delà du cadre local. Pour s'orienter, il dispose d'un outil sûr avec le double index thématique et géographico-onomastique (les deux dimensions sont mêlées dans les noms qu'attribue l'institution municipale à ses administrés juifs), et qui, grâce au travail de M. Lenarz, couvre maintenant l'ensemble des volumes publiés. En revanche, il ne pourra guère suivre de guide : préface et bibliographie sont réduites au minimum, et l'on ne saurait ici trop renvoyer aux travaux collectifs 
récemment consacrés à l'histoire des Juifs de Francfort, et alors recensés dans le Bulletin. L'ouvrage, pourtant, a une cohérence forte : au travers des "livres des bourgmestres ", protocoles et autres enregistrements des activités du Conseil ici présentés, et même si l'ouvrage s'ouvre volontiers à des sources (publiées ou non) provenant de l'environnement de la ville, c'est l'institution municipale qui en est le cœur, et ce sont aussi son quotidien et ses ambiguïtés que l'on perçoit. Ce prisme documentaire ne vise pas à l'exhaustivité ; le chercheur pourra ainsi le compléter par l'exploration des archives judiciaires (y compris celles du Tribunal de la Chambre impériale) aujourd'hui bien indexées. Il permet néanmoins une perception privilégiée des enjeux entourant la coexistence, dans une même ville, de plusieurs confessions, mais aussi, bien plus largement, du rapport à l'institution municipale elle-même. Grâce à cette publication, l'univers presque clos d'une ruelle ouvre sur tant d'horizons que tout chercheur germaniste pourra avec délices y plonger son regard.

Vincent DEMONT (Lycée Honoré de Balzac, Mitry-Mory) 